\title{
Risk factors for Clostridium difficile infection in surgical patients hospitalized in a tertiary hospital in Belgrade, Serbia: a case-control study
}

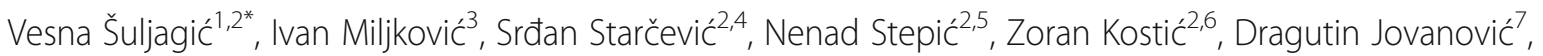 \\ Jelena Brusić-Renaud ${ }^{8}$, Biljana Mijović ${ }^{9}$ and Sandra Šipetić-Grujičićc ${ }^{10}$
}

\begin{abstract}
Background: The objective of this study was to investigate independent risk factors (RFs) connected with healthcare-associated (HA) Clostridium difficile infection (CDI) in surgical patients, its frequency per surgical wards and in-hospital-mortality at a single hospital.

Methods: Risk factors for the infection were prospectively assessed among surgical patients with laboratory confirmed HA CDI and compared with a control group without HA CDI.

Results: The overall incidence rate of HA CDI was 2.6 per 10000 patient-days. Significant independent RFs for HA CDI were the use of carbapenems ( $P=0.007, \mathrm{OR}: 10.62,95 \% \mathrm{Cl}: 1.93-58.4)$, the admission to intensive care unit $(P=0.004, \mathrm{OR}: 3.00,95 \% \mathrm{Cl}: 1.41-6.40)$, and the administration of 3rd generation cephalosporins $(P=0.014$, OR:2.27, 95\% Cl:1.18-4.39). Patients with HA CDI had significantly higher in-hospital mortality compared to controls (P: 0.007; OR: $8.95 ; 95 \%$ Cl: 1.84-43.43).

Conclusions: $\mathrm{CDI}$ is an important HA infection in population of surgical patients and this study emphasizes the importance of the wise use of antibiotics, and other infection control strategies in order to prevent HA CDI, and to decrease the incidence and in-hospital mortality rate.
\end{abstract}

Keywords: Clostridium difficile, Incidence, Risk factors, In-hospital mortality, Surgical patients

\section{Background}

During the current century the epidemiology of Clostridium difficile (C.difficile) infections (CDI) has changed rapidly, with increases noted in the incidence of diseases internationally, and in the reports of CDI outbreaks within healthcare institutions in the USA, Canada and Europe. The increase of CDI incidence was partly associated with the epidemic emergence of a new $\mathrm{C}$. difficile ribotype 027 , which was also described to cause more severe infections [1]. CDI became one of the most common healthcare-associated (HA) infections in modern

\footnotetext{
*Correspondence: suljagicv@gmail.com

'Department of Nosocomial Infections Control, Military Medical Academy, 11 000 Belgrade, Serbia

${ }^{2}$ Faculty of Medicine of Military Medical Academy University of Defence,

11000 Belgrade, Serbia

Full list of author information is available at the end of the article
}

medicine. CDI results in a wide spectrum of clinical conditions, including an asymptomatic carrier state; mild, self-limited diarrhea; pseudomembranous colitis; and fulminant colitis. It is associated with the increased morbidity, in-hospital mortality, prolonged hospitalization, and increased costs. The main risk factors for CDI include the administration of antibiotics, patients older than 65 years, multiple co-morbid conditions, previous hospitalization, medical procedures, and long stay in hospitals [2-4]. The reported incidence of HA CDI varies according to the country, the size of institution and ward location, the type of population studied [5-11]. Patients undergoing surgical procedures are at risk of the postoperative HA CDI development. Most studies of risk factors (RFs) for CDI in surgical patients have been conducted in the USA or Western European countries, which 
are characterized by the well-developed healthcare systems $[8-10,12]$. In contrast, the burden of CDI in Serbia, a country in socioeconomic transition and with a resourcelimited healthcare system, is less well studied $[3,11]$. The burden of CDI in surgical patients in Serbia is unclear.

The aim of this study was to investigate independent RFs associated with HA CDI in surgical patients, its frequency per surgical wards and in-hospital-mortality in a tertiary healthcare centre in Serbia.

\section{Methods}

\section{Patients and databases}

The Military Medical Academy (MMA), Belgrade, Serbia, a teaching hospital of the University of Defense, is a 1200-bed tertiary healthcare centre divided into 27 departments. The department of Infection Control performs continuous surveillance of the MMA patients. The surveillance of $\mathrm{HA}$ infections, including CDI, covered patients in surgical clinics of the MMA: Urology, General Surgery, Orthopedics/Traumatology, Neurosurgery, Maxillofacial Surgery, Plastic Surgery/ Burns, Vascular Surgery, Thoracic Surgery, Cardio Surgery, Otorhinolaryngology, and Ophthalmology.

Through regular hospital surveillance of surgical patients we prospectively identified all patients who had new HA, laboratory confirmed postoperative CDI during the study period, from 1st January 2011 to 31st December 2012. Reviewing the clinical chart information on patient characteristics, RFs related to healthcare were collected. We gathered data on the following variables: intrinsic factors (existing at admission) sex, age, Diabetes mellitus, malignancy, and factors related to healthcare including previous hospitalization in other hospitals, intensive care unit (ICU) admission, duration of treatment in ICU, mechanical ventilation, nasogastric tubes, previous use of corticosteroids, histamine-2-receptor antagonists (H2RAs), proton-pump inhibitors (PPIs) and antibiotics (number, type, and duration of used antibiotics). Also, data about in-hospital mortality were recorded.

In the case-control study, every surgical patient with HA CDI was compared with two control patients without CDI. HA CDI was defined as diarrhea ( $\geq 3$ daily) which was acquired more than three days after admission to the surgical department and detection of $C$. difficile toxins $\mathrm{A}$ and $\mathrm{B}$ in a stool sample, which was derived more than three days after admission. Control patients were matched to the cases according to the inpatient ward, gender, age ( \pm 5 years), and date of surgical operation.

\section{Microbiological testing}

Microbiological testing was performed at the Institute of Medical Microbiology at the MMA. Enzyme immunoassay kits for $C$. difficile toxins $\mathrm{A}$ and $\mathrm{B}$ were used (BIOMERIEUX-VIDAS Clostridium difficile toxins AEB CDAB). Only patients who had never been diagnosed with $C D I$ at the MMA were included in the control group, and only those who had not been diagnosed with CDI before enrolling in the study, were included in the case group, respectively. The Research Ethics Board of the MMA approved the research protocol. All study participants provided the informed written consent.

\section{Statistical analysis}

Incidence rate (IR) was defined as the number of HA CDIs per 10000 patient-days and per 1000 patients treated. The rate of testing (TR) was defined as the number of $C$. difficile toxin tests performed per 10000 patient-days. The inhospital mortality rate was defined as the number of deaths per 100 patients. Data analyses were performed with SPSS, version 21.0 (SPSS, Inc, Chicago, IL). Results were expressed as the mean $\pm \mathrm{SD}$ or as the proportion of the total number of patients. The $\chi^{2}$ test or Fischer exact test were used for categorical variables and relative risk, and their corresponding $95 \%$ confidence intervals $(\mathrm{CI})$ were calculated. For parametric continuous variables, mean values were compared using the Student $t$ test. For nonparametric continuous variables the Mann-Whitney $U$ test was used. RF independently associated with CDI were identified by stepwise logistic regression analysis of variables selected by univariate analysis, with a limit for enetering and removing variables from the model at 0.05 .

\section{Results}

During 2011-2012 in the MMA 29033 surgical patients were treated during 255431 patient-days. A total of 67 surgical patients with CDI were registered (IR: 2.6 per 10000 patient-days or 2.3 per 1000 patients, TR: 8.5 per 10000 patient-days) (Table 1).

Demographic and clinical characteristics of patients in the case and control groups according to ULRA are shown in Table 2. MLRA identified three independent RFs associated with CDI in surgical patients: the previous administration of carbapenems $(P=0.007$, OR:10.62, 95\% CI:1.93-58.4), the 3rd generation of cephalosporins $(P=0.014$, OR:2.27, 95\% CI:1.18-4.39) and admission to the ICU $(P=0.004$, OR:3.00, 95\% CI:1.41-6.40). According to the ULRA, PPIs usage was a significant RF for HA CDI $(P=0.05)$, but it was not a significant independent RF according to MLRA $(P=0.051$, OR:2.7, 95\% CI:1.00-7.19).

In hospital-mortality was significantly higher by 9 -fold in HA CDI compared to control (12\% vs $1.5 \%, P$ : 0.007; OR: 8.95 ; $95 \%$ CI: $1.84-43.43)$. Of 8 deaths in the case group, 6 or $75 \%$ were in the older than 65 . 
Table 1 Incidence rates of Clostridium difficile infections in 11 surgical wards of Military Medical Academy during 2011-2012

\begin{tabular}{llllc}
\hline Ward & $\begin{array}{l}\text { Hospital Inpatient Days/ } \\
\text { Number of patients treated }\end{array}$ & $\begin{array}{l}\text { New cases per } 10000 \\
\text { patient-days }\end{array}$ & $\begin{array}{l}\text { New cases per } \\
1000 \text { patients }\end{array}$ & $\begin{array}{c}\text { Testing frequency per } \\
10000 \text { patient-days }\end{array}$ \\
\hline Urology & $39022 / 5968$ & 1.5 & 1.0 & 6.7 \\
General Surgery & $42063 / 4358$ & 1.7 & 1.6 & 6.4 \\
Traumatology/Orthopaedics & $44139 / 3716$ & 6.1 & 7.2 & 12.5 \\
Neurosurgery & $22546 / 2639$ & 0 & 0 & 4.4 \\
Maxillofacial Surgery & $16829 / 2242$ & 0.6 & 0.4 & 2.4 \\
Plastic Surgery and Burns & $24019 / 2414$ & 4.6 & 4.6 & 11.2 \\
Vascular Surgery & $20175 / 1631$ & 1.5 & 1.8 & 16.9 \\
Thoracic Surgery & $12408 / 1191$ & 0.8 & 0.8 & 7.3 \\
Cardiosurgery & $13842 / 827$ & 6.5 & 10.9 & 14.5 \\
Otorhinolaryngology & $20388 / 4047$ & 1.0 & 0.5 & 2.0 \\
Overall & $255431 / 29033$ & 2.6 & 2.3 & 8.5 \\
\hline
\end{tabular}

\section{Discussion}

Most of epidemiological data about CDI in surgical patients have been limited to North America and West Europe $[8-10,12]$. This study provides data about IR, RF and in-hospital-mortality of HA CDI in surgical patients admitted to the tertiary healthcare centre in the South East Europe.

The overall IR of HA CDI was 2.6 per 10000 patientdays, varied by different wards from 0 in Neurosurgery to more than 6 per 10000 patient-days in Orthopedics/Traumatology and Cardio Surgery. The overall TR was 8.5 per 10000 patient-days varied by different wards from 2.0 in Otorhinolaryngology to 16.9 per 10000 patient-days in Vascular Surgery. Our results of IR were similar to data reported by a coordinating laboratory for Portugal (2.9 for 2011-2012 and 3.0 for 2012-2013), but lower than mean IR of 7.0 of HA CDI (country range 0.7-28.7) in a European, multicentre, prospective, biannual pointprevalence study of CDI in hospitalized patients with diarrhea (EUCLID) (4). In our hospital we have the practice of routine testing of all submitted diarrheal inpatient samples, but our TR in surgical patients in the two-year period was far lower than mean TR in European hospitals (65.8 tests, country range 4.6-223.3) (4).

An association between female gender and CDI has been reported by previous population-based studies from the USA [5]. Similarly to the report of Rodrigues et al. [9], our results showed no significant association between gender and CDI. Advance age is an independent RF for CDI in many studies $[5,9,10]$. RFs specific to older adults are frequent interactions with healthcare systems and age-related changes in physiology, including immune senescence and changes of the gut microbiome [13]. In our study majority of CDI occurred in patients older than 40 years and half in patients older than 65 years. We did not analyze age and sex in the model of MLRA because cases and controls were matched according to those variables.
Among the main findings of this study are the identification of significant independent RFs for CDI in surgical patients, including carbapenems, admission to ICU and the 3rd generation of cephalosporins. The disruption of the normal flora caused by antibiotics allows $C$. difficile to colonize and overgrow within the gastrointestinal tract. Nearly all antibiotics have been implicated in CDI, but certain classes seem to cause higher risk for CDI. Stojanović confirmed in his study that all the groups of antibiotics, except for tetracycline, and trimetoprimsulfamethoxazole, were statistically significant RFs for CDI [3]. The administration of quinolones emerged as the most important RF for CID in Quebec during an epidemic caused by a hipervirulent strain of $C$. difficile [14]. A recent study from England showed that restricting quinolones prescribing was associated with a decline in incidence of CDI [15]. The majority of patients in our study received at least one class of antibiotic. The thirdgeneration cephalosporins were the most commonly used antibiotics in both groups and an independent RF for CDI. The study of Korean authors showed that the use of cephalosporins increased the risk for CDI [4]. Also, the use of carbapenems, in addition to having the higher frequency in the case group, was an independent RF for CDI in our study. The study of Metzger et al. showed that carbapenems usage was associated with CDI in ULRA, but didn't retain significance as an independent RF in MLRA [16].

The admission to ICU was significantly associated with CDI in our patients as reported before $[4,9]$. Critically ill patients in ICU share many of the RFs for developing CDI such as: severe underlying diseases, antibiotic exposure, gastric acid suppression with H2RAs or PPIs, the use of mechanical ventilation, and nasogastric tubes [17].

However, in a meta-analysis, Kwok et al. demonstrated the possible association between the PPI use and the incident and recurrent CDI. This risk was further 
Table 2 Distribution of cases and controls according to their demographic and clinical characteristics: results of univariate analysis

\begin{tabular}{|c|c|c|c|}
\hline \multirow[t]{2}{*}{ Variable } & \multirow{2}{*}{$\begin{array}{l}\text { Case } N^{\circ}(\%) \\
n=67\end{array}$} & \multirow{2}{*}{$\begin{array}{l}\text { Controls } N^{\circ}(\%) \\
n=134\end{array}$} & \multirow[t]{2}{*}{$p$ value } \\
\hline & & & \\
\hline Male & $32(47.8)$ & $64(47.8)$ & 1.00 \\
\hline \multicolumn{4}{|l|}{ Age } \\
\hline$\leq 40$ & $2(2.9)$ & $5(3.7)$ & 0.786 \\
\hline $41-64$ & $32(47.8)$ & $58(43.3)$ & 0.547 \\
\hline$\geq 65$ years & $33(49.2)$ & $71(52.9)$ & 0.618 \\
\hline Diabetes mellitus & $10(14.9)$ & $15(11.2)$ & 0.451 \\
\hline Malignacy & $14(20.9)$ & $22(16.4)$ & 0.436 \\
\hline Previous hospitalization & $13(19.4)$ & $19(14.1)$ & 0.342 \\
\hline ICU admission & $22(32.8)$ & $19(14.1)$ & 0.003 \\
\hline$\geq 5$ days in ICU & $67(100.0)$ & $121(90.3)$ & 0.051 \\
\hline Nasogastric tube & $5(7.4)$ & $1(0.7)$ & 0.032 \\
\hline Mechanical ventilation & $4(5.9)$ & $0(0.0)$ & 0.032 \\
\hline Proton-pump inhibitors & $13(19.4)$ & $8(5.9)$ & 0.005 \\
\hline $\mathrm{H} 2$ receptor antagonist & $40(59.7)$ & $62(46.2)$ & 0.074 \\
\hline Corticosteroides & $4(5.9)$ & $1(0.7)$ & 0.059 \\
\hline One antibiotic & $32(47.8)$ & $85(63.4)$ & 0.035 \\
\hline Days of usage an antibiotic & $5.13 \pm 2.14$ & $4.40 \pm 2.27$ & 0.120 \\
\hline Two antibiotics & $20(29.9)$ & $27(20.1)$ & 0.128 \\
\hline Days of usage two antibiotics & $5.85 \pm 3.79$ & $4.63 \pm 2.13$ & 0.167 \\
\hline Three antibiotics & $9(13.4)$ & $5(3.7)$ & 0.017 \\
\hline Days of usage three antibiotics & $7.89 \pm 5.89$ & $5.60 \pm 2.07$ & 0.423 \\
\hline Four antibiotics & $4(6.0)$ & $2(1.5)$ & 0.103 \\
\hline Days of usage four antibiotics & $8.75 \pm 4.35$ & $7.00 \pm 2.83$ & 0.642 \\
\hline Cephalosporins 1st gen. & $15(22.4)$ & $33(24.6)$ & 0.726 \\
\hline $\begin{array}{l}\text { Days of usage cephalosporins } \\
1 \text { st gen. }\end{array}$ & $1.15 \pm 2.47$ & $1.04 \pm 2.16$ & 0.742 \\
\hline Cephalosporins 2nd gen. & $14(20.9)$ & $25(18.7)$ & 0.705 \\
\hline $\begin{array}{l}\text { Days of usage cephalosporins } \\
\text { 2nd gen. }\end{array}$ & $1.18 \pm 2.50$ & $0.96 \pm 2.25$ & 0.537 \\
\hline Cephalosporins 3rd gen. & $42(62.7)$ & $62(46.3)$ & 0.029 \\
\hline $\begin{array}{l}\text { Days of usage cephalosporins } \\
\text { 3rd gen. }\end{array}$ & $4.39 \pm 4.59$ & $2.51 \pm 3.25$ & 0.001 \\
\hline Aminiglycosides & $7(10.4)$ & $18(13.4)$ & 0.546 \\
\hline $\begin{array}{l}\text { Days of usage } \\
\text { Aminoglycosides }\end{array}$ & $0.91 \pm 3.58$ & $0.66 \pm 2.10$ & 0.528 \\
\hline Quinolones & $6(8.9)$ & $4(3.0)$ & 0.080 \\
\hline Days of usage Quinolones & $0.52 \pm 1.76$ & $0.16 \pm 0.94$ & 0.056 \\
\hline Sulfonamides & $3(4.5)$ & $5(3.7)$ & 0.799 \\
\hline Days of usage Sulfonamides & $0.25 \pm 1.26$ & $0.15 \pm 0.86$ & 0.491 \\
\hline Carbapenems & $6(9.0)$ & $2(1.5)$ & 0.024 \\
\hline Days of usage Carbapenems & $0.62 \pm 2.10$ & $0.10 \pm 0.85$ & 0.014 \\
\hline
\end{tabular}

increased by concomitant use of antibiotics and PPI, whereas H2RAs may be less harmful [18]. In our study, according to ULRA, both groups of patients received H2RAs $(59.7 \%$ of cases and $46.2 \%$ controls) more frequently than PPIs (19.4\% and 5.9\%), but only PPIs significantly increased the risk of CDI without being a significant independent RF. Also, mice model demonstrated that PPIs administration can increase the severity of CDI induced by an antibiotic cocktail [19]. Medications that suppress gastric acid have been associated with the alteration of gastrointestinal flora and the increased susceptibility to gastrointestinal infections [20].

The mortality rate in patients with CDI in this study was $12.1 \%$ and significantly higher than in the control group. Also, it is higher than it was reported in Veterans Health Administration (12.1\% vs 5.3\%) [8]. This difference is explained by the different levels of healthcare and treatment of patients in hospitals in Serbia and the USA.

Of 8 deaths in the case group, 6 or $75 \%$ were in the older than 65. CDI was not the primary cause of death but it was mentioned in the clinical chart information. A systematic review of unfavorable outcomes of CDI (68 studies), based on publications from 1978 until 2013, showed that mortality was associated with age, co-morbidities, hypo-albuminemia, leucocytosis, acute renal failure, and infection with ribotype 027 [21].

Last data from a European, multicentre, prospective, biannual point-prevalence study of CDI showed that overall prevalence of ribotype 027 has risen more than three-fold (from 5\% to 18\%) and high endemicity of ribotype 027 has shifted from the UK and Ireland in 2008, to Germany and Eastern Europe in 2012-13 [6, 7]. The study of Rupnik et al. analyzed PCR ribotype distribution of 249 C. difficile isolates received for typing from six hospital settings from South Europe (the MMA was not included) in time period from 2008 to 2015 and showed that PCR ribotype 027 and related ribotype 176 were detected in outbreaks in Croatia, Bosnia and Herzegovina and Serbia [22]. Some PCR ribotypes are more often associated with severe diseases and/or are easily transmitted and linked to outbreaks. In our study we did not know if all those cases were from the outbreak because of the inability of laboratory pathogen isolation and the impossibility of determining its ribotype.

Important limitation of this study is that CDI testing was based on toxin A/B enzyme immunoassay (EIA) as the only diagnostic procedure in laboratory (no EIA detecting glutamate dehydrogenase, no nucleic acid amplification tests, no isolation of $C$. difficile and detection of toxigenic isolates). This procedure has shown poor sensitivity of less than $50 \%$ in studies of Shin [23] and Swindells [24]. The meta-analysis of Crobach et al. showed that no single test can be used as a stand-alone 
test for diagnosed CDI as a result of inadequate positive predictive values at low CDI prevalence [25]. C. difficile toxins can degrade at room temperature and the quality of CDI diagnostic also depends on transport time of the samples in the respective settings of the MMA. Both, the low rate of test performance in general and limitations of diagnostic test system, which we used, make it very likely that the actual incidence of CDI in our study was markedly higher.

Another limitation is the possibility of confounding variables that were not examined in our study. Although confounding variables were chosen after an exhaustive search of the literature, the potential for oversight and exclusion does exist. We tried to find all of the data in order to gain an understanding of the RF; we did not include some parameters, namely the diagnosis upon admission, all comorbidities, durations of the hospital stays, PPIs exposure in previous 30 days, the duration of PPIs and H2RA use, and outpatient antibiotic use, and analyzing these factors could have enhanced the relevance of our results. Furthermore, we did not evaluate the CDI cases and the controls in relation to the sex, age and wards in which they had undergone treatment, because CDI cases and controls were matched according to them.

Another limitation is that we performed case-control study and that we have small sample size.

The strengths of our study include its setting in a teaching hospital, and its 2-year duration. ULRA and MLRA strengthened the evidence.

\section{Conclusions}

The results of the present study are valuable in documenting the relations between RFs and CDI in patients undergoing surgery and contribute to improve quality of health care. CDI is an important HA infection in population of surgical patients and this study emphasizes the importance of the wise use of antibiotics, and other infection control strategies to prevent HA CDI, decrease incidence and in- hospital mortality rate.

\section{Abbreviations \\ C.difficile: Clostridium difficile; CDI: Clostridium difficile infection; Cl: Confidence intervals; H2RAs: Histamine-2-receptor antagonists; HA: Healthcare-associated ICU: Intensive care unit; IR: Incidence rate; MLRA: Multivariate logistic regression analysis; MMA: Military Medical Academy; PPIS: Proton-pump inhibitors; RF: Risk factors; TR: Testing rate}

\section{Acknowledgments}

Not applicable.

\section{Funding}

This study was supported by internal funding of the Military Medical Academy.

\section{Availability of data and materials}

All data generated or analysed during this study are included in this published article.

\section{Authors' contributions}

ŠV, ŠGS, KZ participated in design of study. MI, SS, SN, BRJ took part in acquisition of data. JD carried out the enzyme immunoassay for $C$. difficile toxins $A$ and $B$. MB and ŠGS performed the statistical analysis. $\breve{V} V$ coordination and helped to draft the manuscript. All authors read and approved the final manuscript.

\section{Competing interests}

The authors declare that they have no competing interests.

\section{Consent for publication}

Not applicable.

\section{Ethics approval and consent to participate}

The study was reviewed and approved by the the Research Ethics Board of the MMA(number MF VMA/1/13-15).

\section{Publisher's Note}

Springer Nature remains neutral with regard to jurisdictional claims in published maps and institutional affiliations.

\section{Author details}

${ }^{1}$ Department of Nosocomial Infections Control, Military Medical Academy, 11 000 Belgrade, Serbia. ${ }^{2}$ Faculty of Medicine of Military Medical Academy University of Defence, 11000 Belgrade, Serbia. ${ }^{3}$ Institute of Epidemiology, Military Medical Academy, 11000 Belgrade, Serbia. ${ }^{4}$ Clinic for Orthopedic Surgery and Traumatology, Military Medical Academy, 11000 Belgrade, Serbia. ${ }^{5}$ Clinic for Plastic Surgery and Burns, Military Medical Academy, 11000 Belgrade, Serbia. ${ }^{6}$ Clinic for General Surgery, Military Medical Academy, 11 000 Belgrade, Serbia. ${ }^{7}$ Institute of Microbiology Military Medical Academy, 11 000 Belgrade, Serbia. ${ }^{8}$ Sector for Pharmacy, Military Medical Academy, 11000 Belgrade, Serbia. ${ }^{9}$ Faculty of Medicine, University of East Sarajevo, 73300 Foča, Republic of Srpska, Bosnia and Herzegovina. ${ }^{10}$ Institute of Epidemiology, Faculty of Medicine, University of Belgrade, 11000 Belgrade, Serbia.

Received: 13 October 2016 Accepted: 17 March 2017

Published online: 27 March 2017

\section{References}

1. Freeman J, Bauer MP, Baines SD, Corver J, Fawley WN, Goorhuis B, et al. The changing epidemiology of Clostridium difficile infections. Clin Microbiol Rev. 2010;23:529-49.

2. Magee G, Strauss ME, Thomas SM, Brown H, Baumer D, Broderick KC. Impact of Clostridium difficile-associated diarrhea on acute care length of stay, hospital costs, and readmission: A multicenter retrospective study of inpatients, 2009-2011. Am J Infect Control. 2015;43(11):1148-53.

3. Stojanović P. Analysis of risk factors and clinical manifestations associated with Clostridium difficile disease in Serbian hospitalized patients. Braz J Microbiol. 2016:47(4):902-10.

4. Cho SM, Lee JJ, Yoon HJ. Clinical risk factors for Clostridium difficileassociated diseases. Braz J Infect Dis. 2012;16:256-61.

5. Lessa FC, Mu Y, Bamberg WM, Beldavs ZG, Dumyati GK, Dunn JR, et al. Burden of Clostridium difficile infection in the United States. N Engl J Med. 2015;372:825-34.

6. Davies KA, Longshaw CM, Davis GL, Bouza E, Barbut F, Barna Z, et al. Underdiagnosis of Clostridium difficile across Europe: the European, multicentre, prospective, biannual, point-prevalence study of Clostridium difficile infection in hospitalised patients with diarrhoea (EUCLID). Lancet Infect Dis. 2014;14:1208-19.

7. Bauer MP, Notermans DW, van Benthem BH, Brazier JS, Wilcox MH, Rupnik M, ECDIS Study Group, et al. Clostridium difficile infectioninEurope: a hospital-based survey. Lancet. 2011;377:63-73.

8. Li X, Wilson M, Nylander W, Smith T, Lynn M, Gunnar W. Analysis of Morbidity and Mortality Outcomes in Postoperative Clostridium difficile Infection in the Veterans Health Administration. JAMA Surg. 2015;25:1-9.

9. Rodrigues MA, Brady RR, Rodrigues J, Graham C, Gibb AP. Clostridium difficile infection in general surgery patients; identification of high-risk populations. Int J Surg. 2010;8:368-72. 
10. Abdelsattar ZM, Krapohl G, Alrahmani L, Banerjee M, Krell RW, Wong SL, et al. Postoperative Burden of Hospital-Acquired Clostridium difficile Infection. Infect Control Hosp Epidemiol. 2015;36:40-6.

11. Šuljagić V, Đorđević D, Lazić S, Mijović B. Epidemiological characteristics of nosocomial diarrhea caused by Clostridium difficile in a tertiary level hospital in Serbia. Srp Arh Celok Lek. 2013;141:482-9.

12. Skovrlj B, Guzman JZ, Silvestre J, Al Maaieh M, Quereshi SA. Clostridium difficile colitis in patients undergoing lumbar spine surgery. Spine. 2014;39:E1167-1173.

13. Jump RL. Clostridium difficile infection in older adults. Aging health. 2013;9(4):403-14.

14. Pépin J, Saheb N, Coulombe MA, Alary ME, Corriveau MP, Authier S, et al. Emergence of fluoroquinolones as the predominant risk factor for Clostridium difficile-associated diarrhea: a cohort study during an epidemic in Quebec. Clin Infect Dis. 2005:41(9):1254-60.

15. Dingle KE, Didelot X, Quan TP, Eyre DW, Stoesser N, Golubchik T, et al. Effects of control interventions on Clostridium difficile infection in England: an observational study. Lancet Infectious Diseases. 2017

16. Metzger R, Swenson BR, Bonatti H, Hedrick TL, Hranjec T, Popovsky KA, et al. Identification of risk factors for the development of Clostridium difficileassociated diarrhea following treatment of polymicrobial surgical infections. Ann Surg. 2010:251(4):722-7.

17. Riddle DJ, Dubberke ER. Clostridium difficile infection in the intensive care unit. Infect Dis Clin North Am. 2009;23(3):727-43.

18. Kwok CS, Arthur AK, Anibueze Cl, Singh S, Cavallazzi R, Loke YK. Risk of Clostridium difficile infection with acid suppressing drugs and antibiotics: meta-analysis. Am J Gastroenterol. 2012;107:1011-9.

19. Hung YP, Ko WC, Chou PH, Chen YH, Lin HJ, Liu YH, et al. Proton pump inhibitor exposure aggravates Clostridium difficile associated colitis: evidences from a mouse model. J Infect Dis. 2015;212:654-63.

20. Williams $C$. Occurrence and significance of gastric colonization during acidinhibitory therapy. Best Pract Res Clin Gastroenterol. 2001;15(3):511-21.

21. Chakra CN, Pepin J, Sirard S, Valiquette L. Risk factors for recurrence, complications and mortality in Clostridium difficile infection: a systematic review. PLoS One. 2014;9(6):e98400.

22. Rupnik M, Andrasevic AT, Dokic ET, Matas I, Jovanovic M, Pasic S, et al. Distribution of Clostridium difficile PCR ribotypes and high proportion of 027 and 176 in some hospitals in four South Eastern European countries. Anaerobe. 2016:42:142-4.

23. Shin S, Kim M, Kim M, Lim H, Kim H, Lee K, et al. Evaluation of the Xpert Clostridium difficile assay for the diagnosis of Clostridium difficile infection. Ann Lab Med. 2012;32:355e8.

24. Swindells J, Brenwald N, Reading N, Oppenheim B. Evaluation of diagnostic tests for Clostridium difficile infection. J Clin Microbiol. 2010:48:606e8.

25. Crobach MJ, Planche T, Eckert C, Barbut F, Terveer EM, Dekkers OM, Wilcox $\mathrm{MH}$, Kuijper EJ. European Society of Clinical Microbiology and Infectious Diseases: update of the diagnostic guidance document for Clostridium difficile infection. Clin Microbiol Infect. 2016;22:563-81.

\section{Submit your next manuscript to BioMed Central and we will help you at every step:}

- We accept pre-submission inquiries

- Our selector tool helps you to find the most relevant journal

- We provide round the clock customer support

- Convenient online submission

- Thorough peer review

- Inclusion in PubMed and all major indexing services

- Maximum visibility for your research

Submit your manuscript at www.biomedcentral.com/submit

) Biomed Central 